\title{
SEDENTARY BEHAVIOUR AND PHYSICAL ACTIVITY LEVELS IN EMPLOYEES OF KHYBER
} MEDICAL UNIVERSITY PESHAWAR

Zardad Khan ${ }^{1}$, Rab Nawaz ${ }^{2}$, Muhammad Tariq ${ }^{3}$, Alam Zeb ${ }^{1}$, Ikram Ali $^{4}$, Shahid Alam ${ }^{5}$

\author{
Submitted: October 03, 2020 \\ Accepted: April 22, 2021 \\ Published: June 30, 2021
}

Authors' Affiliation

${ }^{1}$ School of Health Sciences Peshawar

${ }^{2}$ Sarhad University, Peshawar

${ }^{3}$ Prime Teaching Hospital, Peshawar

${ }^{4}$ Institute of Physical Medicine and Rehabilitation, Khyber Medical University Peshawar ${ }^{5}$ Ghazali Institute of Medical Sciences Peshawar

Corresponding Author
Alam Zeb
Assistant Professor,
Department of Physical
Medicine \& Rehabilitation,
School of Health Sciences
Peshawar
E-mail:
alamzebamir92@gmail.com

\section{ABSTRACT}

Introduction: The increase in sedentary behaviour and decrease in physical activity levels are some of the contributing factors to many of the noncommunicable diseases. These non-communicable diseases included obesity, type-II diabetes and cardiovascular problems. Apart from causing financial burden on health care system, these diseases have been reported to cause nearly 1.9 million premature deaths per year. The aim of the study was to measure sedentary behaviour and physical activity levels among employees of Khyber Medical University, Peshawar.

Material \& Methods: A cross-sectional survey was conducted on employees of Khyber Medical University, Peshawar. The total sample size was 172 and the data was collected through convenience sampling by using International Physical Activity Questionnaire (IPAQ) long form. This questionnaire measures physical activity levels and sedentary behaviour at work.

Results: Out of 172 participants, 154 (89.5\%) were male and $18(10.4 \%)$ were female with a mean age of $34.4 \pm 2$ years. According to the levels of physical activity, $49(28.5 \%)$ were less active, $63(36.6 \%)$ were moderately active and $60(34.9 \%)$ were highly active. The average time spent by the participants for sitting was $(8.93 \pm 2.35)$ hours per day. A total of $73.8 \%, 23.3 \%$ and $2.9 \%$ participants could be categorised as having high, moderate and low sedentary behaviour, respectively.

Conclusion: Majority of the participants (two-thirds of the participants) demonstrated a high sedentary behaviour and therefore, needed modification in their daily routine.

Key Words: sedentary behaviour, levels of physical activity, employees, medical university

The authors declared no conflict of interest and agreed to be accountable for all aspects of the work in ensuring that questions related to the accuracy or integrity of any part of the work, are appropriately investigated and resolved. All authors contributed substantially to the planning of research, question designing, data collection, data analysis and write-up of the article.

This article may be cited as: Khan Z, Nawaz R, Tariq M, Zeb A, Ali I, Alam S. Sedentary Behaviour and Physical Activity Levels in Employees of Khyber Medical University Peshawar. Rehman J Health Sci. 2021;3(1). 17-20

\section{INTRDUCTION}

Sedentary behaviour and physical inactivity are serious public health problems that are linked to dangerous outcomes of health. ${ }^{1,2}$ Physical inactivity could lead to several non-communicable diseases which are responsible for many life threatening conditions. ${ }^{3,4}$ Due to the advancements in technology, physical work has fallen resulting in a sedentary lifestyle for most people. 5 , ${ }^{6}$ Sedentary behaviour is defined as a group of activities in which energy consumption is not more than 1.5 METs. It includes activities such as lying, sitting, watching television, playing cards etc. ${ }^{7}$ Physical activity represents all those bodily movements with energy consumption of 3 to 8 METs such as walking, running, swimming, cycling etc. ${ }^{8}$ Lack of physical activity is associated with progression of various illnesses causing 1.9 million early fatalities worldwide per year. ${ }^{9}$ Evidence has shown that a sedentary lifestyle has been associated with many problems like obesity, depression, breast cancer, cancer of the colon, metabolic syndrome, cardiovascular diseases. ${ }^{10,11}$ Sedentary behaviour typically occurs in three main domains; occupation, transport and leisure. Moreover, it includes popular activities such as sitting behind a desk, driving, watching television, using a computer and reading. ${ }^{12}$ It can, therefore, be argued that office workers may be exposed to a higher level of risks of poor health due to the nature of their work. ${ }^{13,14}$ Use of technology in the workplace and societal shifts toward more sedentary occupations have reduced daily energy consumption by more than $100 \mathrm{kcal} /$ day over the past 50 years. This decline has been associated with obesity over the same time period as tracked by the National Health and Nutrition Examination Survey. ${ }^{15}$ Therefore, determining effective strategies to increase physical activity levels at workplace may have public health and clinical significance. ${ }^{16}$

Despite the fact that sedentary behavior is increasing day by day due to growth in office work, efforts have been made in various developed countries targeting sedentary behaviors and the levels of physical activity. However, based on our knowledge, there is limited data available relating to developing countries like Pakistan. Therefore, this study was designed to identify the sedentary behaviors and physical activity levels among the staff of Khyber Medical University, Peshawar.

\section{MATERIAL AND METHODS}

A cross-sectional survey was conducted on the employees of Khyber Medical University, Peshawar, located in Hayatabad, Peshawar. A sample of 176 employees, was calculated using Rao soft calculator. Data was collected by using a convenient sampling technique. The study sample included female and male faculty members, administrative and supporting staff 
from Khyber Medical University, Peshawar. The International Physical Activity Questionnaire (IPAQ) was used to measure the physical activity levels and sedentary behavior during a seven-day period in four different domains; work, commute, gardening and leisure time activity and time spent during sitting.

The physical activity was computed by combining the time for activity of each domain and multiplying with METs of corresponding activity like 8, 6 and 4 for vigorous, moderate and walking, respectively. The total physical activity of the whole week expressed as METs/week was calculated by combining values of the above three activities. These were categorised into three different categories of physical activity, low PA $(<600$ METs/Week), moderate PA (601-3000 METs/week) and high PA (>3000 METs/week). ${ }^{17}$ To measure sedentary behaviour, total time spent was calculated by combining the time spent during sitting or in a reclining posture on weekdays and weekends. The weekly sitting time was converted into hours/day and categorised into low $(<4.7 \mathrm{hr} /$ day $)$, moderate $\quad(4.7-7.4 \mathrm{hrs} /$ day $)$ and high $\geq 7.4 \mathrm{hrs} /$ day. ${ }^{18}$

From each institute of KMU, approval was obtained and then questionnaires were distributed together with consent forms to participants ranging from age 18-60 years, and data was collected. The data was analysed through SPSS using standard procedures of statistics like mean, percentage and standard deviation. Chi-Square test was used to measure the levels of physical activity associated with age, designation and gender.

\section{RESULTS}

A total of 176 participants [ 41 (23.8\%) faculty members, $58(33.7 \%)$ administrative staff and $77(41.4 \%)$ supporting staff (table 1)] participate in this survey. The mean age of the participants was $34.4 \pm 6.234$ years ranging from 23-55 years. The weekly METs consumption was higher in supporting staff (3642.8 \pm 3126 METs $)$ than the faculty $(2347.5 \pm 2305$ METs $)$ and the administrative staff (1869.3 \pm 3185.8 METs). Participants falling within the age group of 18-30 years have the maximum METs consumption (4283.6 \pm 3896.7 METs as shown in table 2). According to the levels of physical activity, 49 (28.5\%) participants could be categorised as low active, 63 (36.6\%) participants moderately active and the remaining 60 (34.9\%) highly active.

More than one third of the adminisåtrative (41.3\%) and the faculty $(39 \%)$ staff were in the category of low physical activity and nearly half of the support staff (49.3\%) were highly active. Gender comparison indicated that about $1 / 3$ of the male $35.7 \%$ were highly active compared to their counterpart females (table 3 ). The average sitting time per day was reported $8.93 \pm 2.35$ hours with administrative staff indicating the highest sitting time $(9.9 \pm 2.68$ hours per day) followed by the faculty $(9.12 \pm 2.81$ hours per day) and the support staff $(8.24 \pm 2.23$ hours per day).

\section{DISCUSSION}

This study highlights that the workplace and the type of job affects the levels of physical activity and alters the lifestyle from being physically active to sedentary. In this study administrative, faculty and supporting staff have different levels of physical activity with merely one-third of them falling into the highly active category. The administrative staff exhibit a more sedentary behaviour at an average sitting time of more than nine hours per 18 day. In a study on Warszawa's employees of bank and civil administration, the average sitting time was 9.7 hours which is higher than this study, while in terms of physical activity, $4 \%$ of them indicated higher physical activity. A low level of physical activity was noted in about $70 \%$ of local administrative employees in $50 \%$ of bank officials and $35 \%$ of workers of civil administration which implied no similarity with this study. In $46 \%$ participants, moderate and in $4 \%$ high physical activity was noted, which is contradicting to findings of our study. ${ }^{17}$

A study conducted in Dohuk Iraq, on teaching and supporting staff in the education sector indicated that among the participants, more than $56.6 \%$ of the teaching staff and $44 \%$ of the supporting staff were highly active in which are not in accordance to our findings. Females were more active than males. $41.5 \%$ females and $37.5 \%$ males reported high physical activity whereas the current study concluded that males were more in high physical activity level. In age groups $18-29$ years, $42.3 \%$ were more active than in 30-44 years (37\%) and $45-64$ years $37.8 \%$ in high physical activity although there was no significant difference. ${ }^{19}$

According to the study conducted on the office employees of Albania, the average time spent in sedentary lifestyle was about 10.2 hours per day, same in all groups, which is higher than the findings of this study. In $60 \%$ of the employees, low physical activity was noted, which is contrary to the findings of our study. In $29 \%$ of office workers, MPA was noted and HPA was reported in $11 \%$ participants in current study. ${ }^{20}$ According to another study which was conducted on physicians using the same tool reported that $68.4 \%$ participants were on LPA category, 'MPA' was noted in $28.4 \%$ of the subjects and HPA was noted in only $3.2 \%$. Males were reported more active in 'HPA' $4.3 \%$ and female $1.3 \%$. In gender difference, $80 \%$ of the female and $60 \%$ of the male reported LPA, there was a significant difference, which varies from current study. ${ }^{21}$ While in the Brazilian adult population, the average level of physical activity was $41 \%$, being higher than our study at $28 \% .^{22}$

In Saudi Arabia, $40 \%$ of the adults showed low physically activity, which is worse than our results at $34.3 \%$. Similarly, at $43 \%$ the male participants demonstrated low physical activity level compared with females at $34 \%$. This result is dissimilar to our findings where activity level is higher among males than female participants. PA level was decreasing with increasing age, low physically active participants were $36.35 \%$ in 15-29 years and $36.4 \%$ in $30-44$ years and up to $50 \%$ in 45-60 years with a significant difference. ${ }^{23}$

\section{CONCLUSION}

Sedentary behaviour and physical inactivity are a global health issue and office workers are more affected. The administrative staff exhibit a more sedentary behaviour than faculty and support staff. Males are more active than females.

\section{REFERENCES}

1. Bauman A, Ainsworth BE, Sallis JF, et al. The descriptive epidemiology of sitting: a 20-country comparison using the International Physical Activity Questionnaire (IPAQ). American journal of preventive medicine. 2011;41(2):228-235. 
2. Buckworth J, Nigg C. Physical activity, exercise, and sedentary behavior in college students. Journal of American college health. 2004;53(1):28-34.

3. Fagaras S-P, Radu L-E, Vanvu G. The level of physical activity of university students. Procedia-Social and Behavioral Sciences. 2015;197:1454-1457.

4. Fountaine CJ, Piacentini M, Liguori GA. Occupational sitting and physical activity among university employees. International journal of exercise science. 2014;7(4):295.

5. Haskell WL, Lee I-M, Pate RR, et al. Physical activity and public health: updated recommendation for adults from the American College of Sports Medicine and the American Heart Association. Circulation. 2007;116(9):1081.

6. Healy GN, Clark BK, Winkler EA, Gardiner PA, Brown WJ, Matthews CE. Measurement of adults' sedentary time in population-based studies. American journal of preventive medicine. 2011;41(2):216-227.

7. Matthews CE, Chen KY, Freedson PS, et al. Amount of time spent in sedentary behaviors in the United States, 2003-2004. American journal of epidemiology. 2008;167(7):875-881.

8. $\quad \mathrm{Ng} \mathrm{SW}$, Popkin BM. Time use and physical activity: a shift away from movement across the globe. Obesity reviews. 2012;13(8):659-680.

9. Organization WH. The world health report 2002: reducing risks, promoting healthy life. World Health Organization; 2002.

10. Cotten E. Reducing Sedentary Behaviour In University Students Using A Text Message-Based Intervention. 2015;

11. Meeusen R, Schaefer S, Tomporowski P, Bailey R. Physical activity and educational achievement: Insights from exercise neuroscience. Routledge; 2017.

12. BAVLI Ö. Investigation the physical activity level of physical education students. International Journal of New Trends in Arts, Sports \& Science Education (IJTASE). 2014;3(1)

13. Owen N, Leslie E, Salmon J, Fotheringham MJ Environmental determinants of physical activity and sedentary behavior. Exerc Sport Sci Rev. 2000;28(4):153-158.

14. Rosenberg DE, Bull FC, Marshall AL, Sallis JF, Bauman AE. Assessment of sedentary behavior with the International Physical Activity Questionnaire. Journal of Physical Activity and Health. 2008;5(s1):S30-S44.

15. Straker L, Healy G, Atherton R, Dunstan D. Excessive occupational sitting is not a" safe system of work": time for doctors to get chatting with patients. Medical Journal of Australia. 2014;3:138-140.

16. Jurakić D, Pedišić Ž, Andrijašević M. Physical activity of Croatian population: cross-sectional study using International Physical Activity Questionnaire. Croatian medical journal. 2009;50(2):165-173.

17. Biernat E, Tomaszewski P, Milde K. PHYSICAL ACTIVITY OF OFFICE WORKERS. Biology of sport. 2010;27(4)

18. Brown W, Miller Y, Miller R. Sitting time and work patterns as indicators of overweight and obesity in Australian adults. International journal of obesity. 2003;27(11):1340-1346.

19. Agha S, Al Dobbagh S. Level of physical activity among teaching and support staff in the education sector in Dohuk, Iraq. EMHJ-Eastern Mediterranean Health Journal, 16 (12), 1278-1284, 2010. 2010;

20. Bozo D, Pano G, Çitozi R. Assessment of physical activity level in office employees groups in Albania. 2013;

21. Reshidi FSA. Level of physical activity of physicians among residency training program at Prince Sultan Military Medical City, Riyadh, KSA 2014. International journal of health sciences. 2016;10(1):39. 22. Alves JGB, Figueiroa JN, Alves LV. Prevalence and predictors of physical inactivity in a slum in Brazil. Journal of Urban Health. 2011;88(1):168-175.

23. Al-Hazzaa HM. Health-enhancing physical activity among Saudi adults using the International Physical Activity Questionnaire (IPAQ). Public health nutrition. 2007;10(1):59-64. 
Table 1: Demographic Data

\begin{tabular}{|lll|}
\hline Variables & Frequency & Percentage \\
Faculty & 41 & $23.8 \%$ \\
Administrative & 58 & $33.7 \%$ \\
Supportive & 73 & $42.4 \%$ \\
Age & & \\
$18-30$ & 51 & $29.6 \%$ \\
$31-45$ & 114 & $66.2 \%$ \\
$46-60$ & 7 & $4.1 \%$ \\
Gender & & \\
Male & 154 & $89.5 \%$ \\
Female & 18 & $10.4 \%$ \\
Marital status & & \\
Married & 133 & $77.3 \%$ \\
Unmarried & 39 & $22.6 \%$ \\
\hline
\end{tabular}

Table 2: Weekly METs consumption

\begin{tabular}{|lllll|}
\hline Variables & Vigorous & Moderate & Walk & Grand total \\
Mean \pm SD & Mean \pm SD & Mean \pm SD & $\begin{array}{l}\text { Mean } \pm \text { SD } \\
\text { Faculty }\end{array}$ \\
Administrative & $403.90 \pm 1234.8$ & $1048.2 \pm 1546.3$ & $895.4 \pm 1107.9$ & $2347.5 \pm 2305.0$ \\
Supportive & $320.0 \pm 1158.0$ & $565.43 \pm 1114.78$ & $936.23 \pm 1290.37$ & $1869.3 \pm 3185.8$ \\
age & $969.9 \pm 1619.0$ & $1140.2 \pm 1913.5$ & $1466.2 \pm 1482.7$ & $3642.8 \pm 3126.6$ \\
$18-30$ & & & & \\
$31-45$ & $957.6 \pm 1590.2$ & $1615.5 \pm 2241.6$ & $1583.4 \pm 1543.7$ & $4283.6 \pm 3896.7$ \\
$46-60$ & $500.7 \pm 1349.1$ & $654.1 \pm 1160.8$ & $957.1 \pm 1245.0$ & $2122 \pm 2403.4$ \\
Gender & $0.00 \pm 0.00$ & $291.42 \pm 659.70$ & $1169.1 \pm 1062.8$ & $1460.6 \pm 1644.8$ \\
Male & & & & \\
Female & $680.0 \pm 1479.3$ & $858.2 \pm 1564.7$ & $1226.1 \pm 1395$ & $2813.9 \pm 3152$ \\
Married & $66.66 \pm 282.8$ & $1490.8 \pm 1888.6$ & $512.4 \pm 725.2$ & $2069.9 \pm 2109.7$ \\
Unmarried & $574.4 \pm 1380.6$ & $742.1 \pm 1342.8$ & $1037.8 \pm 1269.9$ & $2392.7 \pm 2588.6$ \\
& $756.9 \pm 1535.7$ & $1546.1 \pm 1546.1$ & $1539.2 \pm 1576.5$ & $3906.8 \pm 4139.1$ \\
\end{tabular}

Table 3: Physical Activity Levels

\begin{tabular}{|c|c|c|c|c|c|}
\hline \multirow[b]{2}{*}{ Variables } & \multirow{2}{*}{$\begin{array}{l}\text { Total } \\
\mathrm{N}=172\end{array}$} & \multicolumn{2}{|c|}{ Physical Activity Level } & \multirow[b]{2}{*}{ Low } & \multirow[b]{2}{*}{$\mathrm{P}$} \\
\hline & & High & Moderate & & \\
\hline Administrative & 58 & $10(17.2 \%)$ & $24(41.3 \%)$ & $24(41.3 \%)$ & \multirow{3}{*}{$\mathrm{P}=0.00$} \\
\hline Faculty & 41 & $14(34.1 \%)$ & $11(26.8 \%)$ & $16(39 \%)$ & \\
\hline Supportive & 73 & $36(49.3 \%)$ & $28(38.3 \%)$ & $9(12.3 \%)$ & \\
\hline Age & & & & & \\
\hline $18-30$ & 51 & $27(52.9 \%)$ & $19(37.2 \%)$ & $5(9.8 \%)$ & \multirow{3}{*}{$\mathrm{P}=0.003$} \\
\hline $31-45$ & 114 & $32(28 \%)$ & $41(35.9 \%)$ & $41(35.9 \%)$ & \\
\hline $46-60$ & 7 & $1(14.2)$ & $3(42.85 .5 \%)$ & $3(42.8 \%)$ & \\
\hline Gender & & & & & \\
\hline Male & 154 & $55(35.7 \%)$ & $56(36.6 \%)$ & $43(27.3 \%)$ & \multirow{4}{*}{$\begin{array}{l}\mathrm{P}=0.785 \\
\mathrm{P}=0.21\end{array}$} \\
\hline Female & 18 & $5(27.7 \%)$ & $7(38.7 \%)$ & $6(33.6 \%)$ & \\
\hline Married & 133 & $43(32.3 \%)$ & $48(36 \%)$ & $42(31.5 \%)$ & \\
\hline Unmarried & 39 & $17(43.5 \%)$ & $15(38.4 \%)$ & $7(17.9 \%)$ & \\
\hline
\end{tabular}

